\title{
Community Participation-A Way Forward in Fight against COVID-19 Pandemic
}

\section{Pandve HT* and Kannan S}

Department of Community Medicine, ESIC Medical College, India
Editorial

Volume 4 Issue 4

Received Date: July 11, 2020

Published Date: July 28, 2020

DOI: $10.23880 /$ eij-16000153

Corresponding author: Harshal Tukaram Pandve, Professor and Head, Dept of Community harshalpandve@yahoo.co.in

"The greatness of a community is most accurately measured by the compassionate actions of its members." Coretta Scott King [1]. Community participation is one of the four pillars in primary health care and involves both theory and practice related to the direct involvement of citizens or citizen action groups potentially affected by or interested in a decision or action [2].

Several landmark reports have emphasized the importance of community participation, including the Bhore Committee (1946) [3], Srivastava Committee (1975) [4] and Alma Ata Declaration of 1978 [5]. Recommendations of these committees include social orientation of medical practice, creating para-professionals or semi-professionals from the community and bringing community participation to the fore along with recognizing rights and duties of people to participate in the planning and implementation of healthcare services.

Community participation is the key to public health and has been central in fights against previous epidemics such as Ebola, HIV. Community involvement could play a key role in planning local-level actions in collaboration with local bodies to identify vulnerable households, provide support to the elderly and those in quarantine, develop better communication strategies and help in contact tracing. Each epidemic has its own distinct characteristics. Taking the geographical, sociocultural, or economic context into account and tailoring our response accordingly is of paramount importance. Hence it is critical for communities to play a leading role in planning health care programs.

Social Mobilization Action Consortium, Sierra Leone's largest community engagement initiative during the Ebola outbreak in 2014, trained 2,500 volunteers for implementing the Community-led Ebola Action (CLEA) approach [6]. Talking about the biggest lessons from the Ebola epidemic of 2014, the WHO also pointed out that "community engagement is the one factor that underlies the success of all other control measures" [7].

Globally, where communities are a diverse mix of identities and interests, an exercise such as the CLEA approach, if properly adapted and implemented, could address the specific needs of the different sections of people during various stages of pandemic and also help in assisting authorities to take appropriate action. This could create greater awareness and sensitivity regarding varying needs and conditions of others and direct collective action towards the common objective of pandemic prevention.

Despite concerns over the growing divide within and between communities, there have been instances where communities came together to help each other and also assist those in need. The steps in community participation to COVID 19 [8] are first, invest in co-production in the form of creating dedicated fund for public health, and create spaces to work together, preparedness for future outbreaks. Secondly, work with community groups can be encouraged by the involvement of local body groups and formation of volunteer groups. Third most important in developing countries is commitment to diversity which can be done by planning in such a way to include all sectors of people including marginalized people. Finally, be responsive and transparent in emphasizing on social solidarity and physical distancing while downplaying the mispositioned thrust on 'social' distancing. The openness and clarity in conveying a message as a part of epidemic response as done by Director General of World Health Organization fortnightly had been very effective in putting a stop to the spread of rumours, stigmatising, stereotypical and communalizing news. Checklist [9] comprising mapping the high risk areas, contact tracing, spreading the correct information, partnership with NGOs and feedback is of practical application and effective community participation. 


\section{Epidemiology International Journal}

To conclude community participation thus being a trump card reduces the immediate damage from the COVID-19 pandemic and, crucially, of building future resilience and lessons learnt can be adopted to primordially prevent future pandemics.

\section{References}

1. E.L N Katherine, Shartriya C (2018) Social Justice and Parent Partnerships in Multicultural Education Contexts. IGI Global: 336.

2. Lachapelle PR, Austin EK (2014) Community Participation. Encyclopedia of Quality of Life and WellBeing Research 1073-1078.

3. Goel S (2007) From Bhore Committee to National Rural Health Mission: A Critical Review. Internet J Health 7(1): $1-4$.

4. Madan GR (1966) Indian Social Problems (Vol-1): Social Disorganization and Reconstruction. Allied Publishers
610.

5. Rosato M, Laverack G, Grabman LH, Tripathy P, Nair $\mathrm{N}$, et al. (2008) Community participation: lessons for maternal, newborn, and child health. Lancet 372(9642): 962-971.

6. Skrip LA, Bedson J, Abramowitz S, Jalloh MB, Bah S, et al. (2020) Unmet needs and behavior during the Ebola response in Sierra Leone: a retrospective, mixedmethods analysis of community feedback from the Social Mobilization Action Consortium. Lancet Planetary Health 4(2): 74-85.

7. (2020) Community engagement and social mobilization. World Health Organization.

8. Marston C, Renedo A, Miles S (2020) Community participation is crucial in a pandemic. Lancet 395(10238): 1676-1678.

9. Farrington M (2020) Community Engagement During Covid-19. Oxfam: 1-2. 